\title{
The comparative analysis of rocks' resistance to forward-slanting disc cutters and traditionally installed disc cutters
}

\author{
Zhao-Huang Zhang' ${ }^{1} \cdot$ Sun Fei ${ }^{2} \cdot$ Meng Liang $^{2}$
}

Received: 7 July 2015 / Revised: 11 September 2015 / Accepted: 14 October 2015 / Published online: 8 December 2015

(C) The Author(s) 2015. This article is published with open access at Springerlink.com

\begin{abstract}
At present, disc cutters of a full face rock tunnel boring machine are mostly mounted in the traditional way. Practical use in engineering projects reveals that this installation method not only heavily affects the operation life of disc cutters, but also increases the energy consumption of a full face rock tunnel boring machine. To straighten out this issue, therefore, a rock-breaking model is developed for disc cutters' movement after the research on the rock breaking of forward-slanting disc cutters. Equations of its displacement are established based on the analysis of velocity vector of a disc cutter's rock-breaking point. The functional relations then are brought forward between the displacement parameters of a rock-breaking point and its coordinate through the analysis of micro displacement of a rock-breaking point. Thus, the geometric equations of rock deformation are derived for the forward-slanting installation of disc cutters. With a linear relationship remaining between the acting force and its deformation either before or after the leap breaking, the constitutive relation of rock deformation can be expressed in the form of generalized Hooke law, hence the comparative analysis of the variation in the resistance of rock to the disc cutters mounted in the forward-slanting way with that in the traditional way. It is discovered that with the same penetration, strain of the rock in contact with forwardslanting disc cutters is apparently on the decline, in other
\end{abstract}

Zhao-Huang Zhang

zh_zhaohuang@163.com

1 School of Energy, Power and Mechanical Engineering, North China Electric Power University, Beijing 102206, China

2 School of Foreign Languages, North China Electric Power University, Beijing 102206, China words, the resistance of rock to disc cutters is reduced. Thus wear of disc cutters resulted from friction is lowered and energy consumption is correspondingly decreased. It will be useful for the development of installation and design theory of disc cutters, and significant for the breakthrough in the design of full face rock tunnel boring machine.

Keywords Full face rock tunnel boring machine - Disc cutter . Forward-slanting installation $\cdot$ Rock breaking

\section{Introduction}

Tunnel boring machines (TBMs) are currently utilized on a large scale in mining and civil engineering projects. Disc cutters are the most commonly used tools and an important part of TBMs. During the excavation, TBM cutters roll across the tunnel face and continuously expand the crushed zone immediately beneath them. When the wedge edge of disc cutter is pressed into rock surface by large thrust exerted, a small crushed area comes into being under the disc cutters, which is further compacted [1]. The penetration mechanism of the discs has been considered as indentation by many researchers. The main research on mechanism of rock indentation and cutting started in the 1970s, among which are those mentioned as follows: Teale [2] observed that penetration is the essential rock cutting parameter. If there is no penetration, there is no failure. Pariseau and Fairhurst [3] predicted the wedge penetration of rock by means of plasticity analysis. Nishimatsu [4] proposed a rock cutting theory on the basis of the research on the metals. Roxborough and Phillips [5,6] presented the concept of groove-deepening in rock cutting process. In the past decades many other empirical researches have also been carried out to investigate the mechanism of rock fragmentation by Ozdemir and Miller [7], Wang and 
Ozdemir [8], Lindqvist [9], Cook et al. [10], Lindqvist et al. [11], Kou [12], and Liu [13] respectively. A numerical model has been presented by Kou et al. [14] to study the rock fragmentation under the action of a drill bit in terms of rock heterogeneity. Innaurato et al. [15] conducted some tests to simulate the disc cutter actions at the tunnel face by means of an indenter on some rock sample. Gertsch et al. [16] then had a full-scale disc cutting test in the laboratory to investigate the effect of some properties of TBM cutters on its performance prediction in Colorado Red Granite. Liu et al. [17] developed a numerical code R-T2D for the reproduction of progressive process of rock fragmentation by indenters, with observation of the failure process of the rock and the realistic crack pattern under various indenters. Cho et al. [18] also conducted a series of numerical tests using AUTODYN-3D to simulate three-dimensional dynamic failure observed in linear cutting machine tests. Moon and Oh [19] used discrete element method analysis to simulate a multi-indentation to study the optimal rock-cutting phenomena in terms of the interaction of the spacing to penetration ratio with intact rock properties. These achievements were all based on the research with disc cutters traditionally installed, while after the long-term research we discovered the mechanics law of interaction between disc cutters installed slantingly outward and rocks [20,21], and hereafter we also found that the disc cutter installed slantingly can generate a better mechanical effect $[22,23]$. Thus, the rock-breaking model with disc cutters slantingly installed is developed for a further study of the rock fragmentation of disc cutters, a contrastive analysis of fragmentation effects of two models has been made: one is based on the slantingly installed disc cutters and the other traditionally installed disc cutters. This is a new attempt to probe the mechanical features of the interaction between disc cutters and rocks.

\section{Rock-breaking model of a forward-slanting disc cutter blade}

To study in depth the rock-breaking performance of the TBM disc cutter, we divide the installation of the disc cutter into traditional installation, forward-leaning installation, and outward-slanting installation. Traditional installation is the widely used method of installation, namely, the rotational axis of the central disc cutter and that of the frontal disc cutter intersect perpendicularly the rotational axis of the cutter head, and the plane of the transitional disc cutter as well as that of the edge blade is vertical to the cutting profile and their axes intersect the rotational axis of the cutter head. Forward-slanting installation means that the disc cutter installed moves at a proper angle in the rotational direction of the cutter head, the diameter at the maximum penetration point being its axis. In the case of outward-slanting installation, the disc cutter installed moves at a proper angle away from the rotational axis of the cutter head, the tangent line at the maximum penetration point on the blade circle being its axis.

If in the case of traditional installation the plane of the disc cutter blade is $\mathrm{O}^{\prime} \mathrm{ABC}$ and in the case of forward-slanting installation the plane of the disc cutter blade with the installation angle $\alpha$ is $\mathrm{O}_{3} \mathrm{DEC}$, then their relationship can be shown in Fig. 1a. At this instance the line determined by point $\mathrm{G}$ at the disc cutter blade and the rotation center of the disc cutter forms the angle $\theta$ with the radius at the maximum penetration point, thus the rock-breaking speed and interaction at point $\mathrm{G}$ can be expressed as Fig. 1b (the relations between different angles as shown in Fig. 1 is derived from geometric relations). Suppose the rotation axis of the cutter head is $\mathrm{O}_{1} \mathrm{O}_{2}$, in which $\mathrm{O}_{1}$ is the rotation axis of the cutterhead-parallel to the intersection between axis $Z$ and the plane $\mathrm{O}_{1} \mathrm{HG}$; its rotation speed is $\omega$; the rotation center of the disc cutter is $\mathrm{O}_{3}$ (the intersection between the axis of the forward-slanting disc cutter and the plane $\mathrm{O}_{3}$ DEC or the intersection between the axis of the disc cutter traditionally installed and the plane $\mathrm{O}_{3} \mathrm{ABC}$ ), and its rotation speed is $\omega^{\prime}$. According to kinetics: $\omega R_{i}=\omega^{\prime} r$ then:

$\omega^{\prime}=\frac{R_{i}}{r} \omega$

In which, $R_{i}$-installation radius of disc cutter $i ; r$-radius of disc cutter.

Other symbols have the same meaning as before. Suppose the cutting distance of the cutter head per revolution is $h$, according to geometrical relations, the penetration of the disc cutter with the forward-slanting installation angle $\alpha$ is also $h$. According to the geometrical relations and kinetics as shown in Fig. 1a, we have:

$$
\begin{aligned}
V_{G e} & =\omega \overline{O_{1} G}, \\
V_{G r} & =\omega R_{i} .
\end{aligned}
$$

In which, $V_{G e}$-transport motion velocity of point $G$ on the disc cutter edge; $V_{G r}$-the relative motion velocity of point $G$ at the disc cutter edge.

$$
\begin{aligned}
V_{G x}= & V_{G e x}-V_{G r x}=V_{G e} \sin \delta-V_{G r} \cos \theta \sin \alpha \\
= & \omega \overline{O_{1} G} \sin \delta-\omega R_{i} \cos \theta \sin \alpha, \\
V_{G y}= & V_{G e y}-V_{G r y}=V_{G e} \cos \delta \\
& -V_{G r} \cos \theta \cos \alpha=\omega \overline{O_{1} G} \cos \delta \\
& -\omega R_{i} \cos \theta \cos \alpha, \\
V_{G z}= & V_{G r} \sin \theta=\omega R_{i} \sin \theta .
\end{aligned}
$$




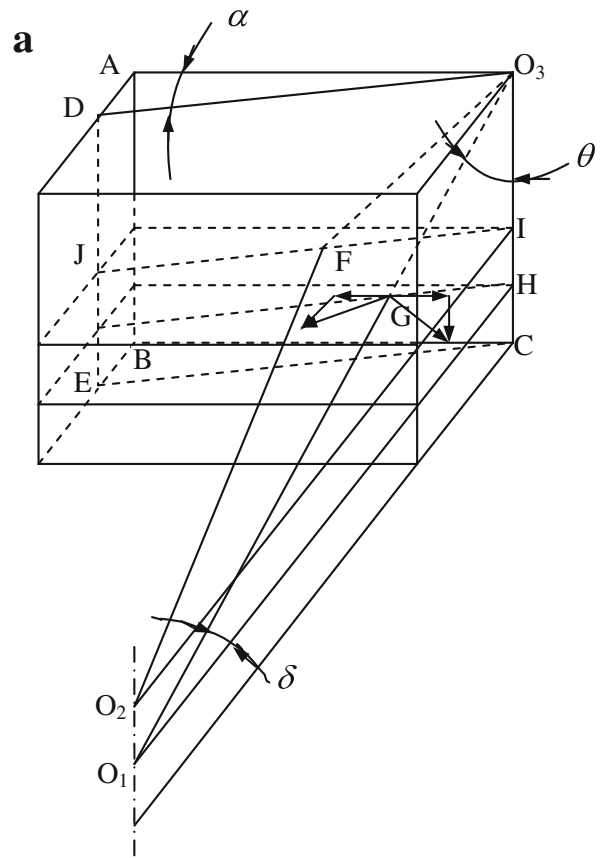

Fig. 1 Analysis of instantaneous rock-breaking rates with disc cutters

This is the rock-breaking model of the disc cutter with forward-slanting installation.

\section{The geometrical equation of rock deformation caused by the disc cutter with forward-slanting installation}

Assuming the penetration of a disc cutter is $h$, then rockbreaking point $F$ completing each penetration results in displacements whose projection on axis $X$, axis $Y$, and axis $Z$ are $X_{G}, Y_{G}$, and $Z_{G}$. They are respectively:

$$
\begin{aligned}
X_{G} & =\int_{V_{G x}} \mathrm{~d} t \\
& =\int_{0}^{\theta}\left(\omega \overline{O_{1} G} \sin \delta-\omega R_{i} \cos \theta \sin \alpha\right) \frac{\mathrm{d} \theta}{\omega^{\prime}} \\
& =\int_{0}^{\theta}\left(\frac{r^{2}}{R_{i}} \sin \theta \cos \alpha-r \cos \theta \sin \alpha\right) \mathrm{d} \theta \\
& =\frac{r^{2} \cos \alpha}{R_{i}}(1-\cos \theta)-r \sin \theta \sin \alpha, \\
\overline{O_{1} G} & =\sqrt{r^{2} \sin ^{2} \theta+R_{i}^{2}-2 R_{i} r \sin \theta \sin \alpha .}
\end{aligned}
$$

Other symbols have the same meaning as before or see Fig. 1. b
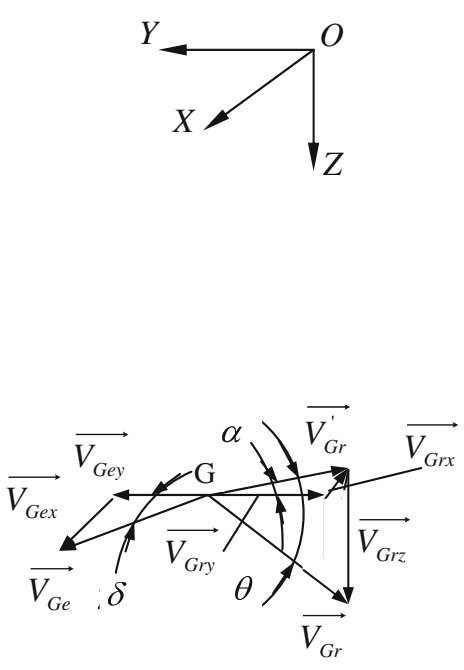

According to geometric relations shown in Fig. 1a, we have:

$$
\begin{aligned}
& \sin \delta=\frac{r \sin \theta \cos \alpha}{\overline{O_{1} G}}, \\
& \cos \delta=\frac{R_{i}-r \sin \theta \sin \alpha}{\overline{O_{1} G}} .
\end{aligned}
$$

According to geometric relations and kinetics shown in Fig. 1b, we have:

$$
\begin{aligned}
Y_{G} & =\int_{G y} V_{G y} \mathrm{~d} t \\
& =\int_{0}^{\theta}\left(\omega \overline{O_{1} G} \cos \delta-\omega R_{i} \cos \theta \cos \alpha\right) \frac{\mathrm{d} \theta}{\omega^{\prime}} \\
& =\int_{0}^{\theta}\left(r-\frac{r^{2}}{R_{i}} \sin \theta \sin \alpha-r \cos \theta \cos \alpha\right) \mathrm{d} \theta \\
& =r \theta-\frac{r^{2}}{R_{i}}(1-\cos \theta) \sin \alpha-r \sin \theta \cos \alpha, \\
Z_{G} & =\int_{G z} V_{G} \mathrm{~d} t=\int_{0}^{\theta} \omega R_{i} \sin \theta \frac{\mathrm{d} \theta}{\omega^{\prime}} \\
& =\int_{0}^{\theta} \omega R_{i} \sin \theta \frac{r}{\omega R_{i}} \mathrm{~d} \theta \\
& =r(1-\cos \theta) .
\end{aligned}
$$




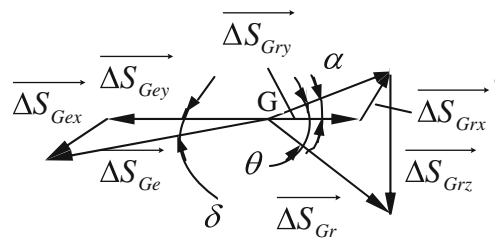

Fig. 2 Vector decomposition of the micro-displacement at rockbreaking point $F$

Assuming the disc cutter rotates past angle $\Delta \theta$ and the cutter head angle $\Delta \delta$, then the transport motion displacement of point $\mathrm{G}$ is $\overrightarrow{\Delta S_{G e}}$ and the relative displacement is $\overrightarrow{\Delta S_{G r}}$. Their directions are shown in Fig. 2 and their sizes are respectively:

$\Delta S_{G e}=\overline{O_{1} G} \Delta \delta, \Delta S_{G r}=r \Delta \theta$, which should satisfy relations: $r \Delta \theta=\overline{O F} \Delta \delta$. Then:

$$
\begin{aligned}
\Delta x= & \Delta S_{G e x}-\Delta S_{G r x}=\Delta S_{G e} \sin \delta \\
& -\Delta S_{G r} \cos \theta \sin \alpha=r \Delta \theta(\sin \delta-\cos \theta \sin \alpha), \\
\Delta y= & \Delta S_{G e y}-\Delta S_{G r y}=\Delta S_{G e} \cos \delta \\
& -\Delta S_{G r} \cos \theta \cos \alpha=r \Delta \theta(\cos \delta-\cos \theta \cos \alpha), \\
\Delta z= & \Delta S_{G r z}=\Delta S_{G r} \sin \theta=r \Delta \theta \sin \theta .
\end{aligned}
$$

Therefore:

$$
\begin{aligned}
\frac{\partial \theta}{\partial x} & =\frac{1}{r(\sin \delta-\cos \theta \sin \alpha)}, \\
\frac{\partial \theta}{\partial y} & =\frac{1}{r(\cos \delta-\cos \theta \cos \alpha)}, \\
\frac{\partial \theta}{\partial z} & =\frac{1}{r \sin \theta} .
\end{aligned}
$$

In accordance with elastic-plastic theory, the effect of rockbreaking edge of disc cutter induces the generation of normal strain $\varepsilon_{x}, \varepsilon_{y}, \varepsilon_{z}$ and shear strain $\gamma_{x y}, \gamma_{y z}, \gamma_{z x}$ at point $G$ on the rock. From Eqs. (4), (5), (6) and (8), we have:

$$
\begin{aligned}
\varepsilon_{x} & =\frac{\partial X_{G}}{\partial x}=\frac{\partial X_{G}}{\partial \theta} \frac{\partial \theta}{\partial x}=\frac{\frac{r}{R_{i}} \sin \theta \cos \alpha-\cos \theta \sin \alpha}{\sin \delta-\cos \theta \sin \alpha} \\
\varepsilon_{y} & =\frac{\partial Y_{G}}{\partial y}=\frac{\partial Y_{G}}{\partial \theta} \frac{\partial \theta}{\partial y}=\frac{1-\frac{r}{R_{i}} \sin \theta \sin \alpha-\cos \theta \cos \alpha}{\cos \delta-\cos \theta \cos \alpha} \\
\varepsilon_{z} & =\frac{\partial Z_{G}}{\partial \theta} \frac{\partial \theta}{\partial z}=1 \\
\gamma_{x y} & =\frac{\partial Y_{G}}{\partial x}+\frac{\partial X_{G}}{\partial y}=\frac{\partial Y_{G}}{\partial \theta} \frac{\partial \theta}{\partial x}+\frac{\partial X_{G}}{\partial \theta} \frac{\partial \theta}{\partial y} \\
& =\frac{1-\frac{r}{R_{i}} \sin \theta \sin \alpha-\cos \theta \cos \alpha}{\sin \delta-\cos \theta \sin \alpha}+\frac{\frac{r}{R_{i}} \sin \theta \cos \alpha-\cos \theta \sin \alpha}{\cos \delta-\cos \theta \cos \alpha} \\
\gamma_{y z} & =\frac{\partial Z_{G}}{\partial y}+\frac{\partial Y_{G}}{\partial z}=\frac{\partial Z_{G}}{\partial \theta} \frac{\partial \theta}{\partial y}+\frac{\partial Y_{G}}{\partial \theta} \frac{\partial \theta}{\partial z} \\
& =\frac{1-\frac{r}{R_{i}} \sin \theta \sin \alpha-\cos \theta \cos \alpha}{\sin \theta} \\
\gamma_{z x} & =\frac{\partial Z_{G}}{\partial x}+\frac{\partial X_{G}}{\partial z}=\frac{\partial Z_{G}}{\partial \theta} \frac{\partial \theta}{\partial x}+\frac{\partial X_{G}}{\partial \theta} \frac{\partial \theta}{\partial z} \\
& =\frac{\frac{r}{\sin \theta}}{\sin \delta-\cos \theta \sin \alpha}+\frac{\frac{r}{R_{i}} \sin \theta \cos \alpha-\cos \theta \sin \alpha}{\sin \theta}
\end{aligned}
$$

This is the geometrical equation of rock deformation in the case of disc cutter with forward-slanting installation.

\section{Rock resistance and analysis}

It is discovered from the indentation experiment and the linear cutting experiment that rocks usually display obvious leap break and that, before and after leap break, the vertical force acting on the disc cutter and its penetration depth basically constitute a linear relationship [24]. In other words, when rock does not have leap break, the relationship between strain and stress can be expressed as generalized Hooke law, that is:

$$
\begin{aligned}
& \varepsilon_{x}=\frac{1}{E^{\prime}}\left[\sigma_{x}-\mu^{\prime}\left(\sigma_{y}+\sigma_{z}\right)\right], \\
& \varepsilon_{y}=\frac{1}{E^{\prime}}\left[\sigma_{y}-\mu^{\prime}\left(\sigma_{z}+\sigma_{x}\right)\right], \\
& \varepsilon_{z}=\frac{1}{E^{\prime}}\left[\sigma_{z}-\mu^{\prime}\left(\sigma_{x}+\sigma_{y}\right)\right], \\
& \gamma_{x y}=\frac{1}{G^{\prime}} \tau_{x y}, \\
& \gamma_{y z}=\frac{1}{G^{\prime}} \tau_{y z}, \\
& \gamma_{z x}=\frac{1}{G^{\prime}} \tau_{z x},
\end{aligned}
$$

in which, $E^{\prime}, \mu^{\prime}$, and $G^{\prime}$ are respectively the parameters related to rock, tools, and rock deformation; $\sigma_{x}, \sigma_{y}, \sigma_{z}, \tau_{x y}$, $\tau_{y z}$, and $\tau_{z x}$ are respectively the stress corresponding to their strain; the other symbols have the same meaning as before.

The above equation may also be expressed as:

$$
\begin{aligned}
\sigma_{x} & =\frac{E^{\prime}}{1-\mu^{\prime}} \varepsilon_{x}+\frac{\mu^{\prime} E^{\prime}}{\left(1-\mu^{\prime}\right)\left(1-2 \mu^{\prime}\right)}\left(\varepsilon_{x}+\varepsilon_{y}+\varepsilon_{z}\right), \\
\sigma_{y} & =\frac{E^{\prime}}{1-\mu^{\prime}} \varepsilon_{y}+\frac{\mu^{\prime} E^{\prime}}{\left(1-\mu^{\prime}\right)\left(1-2 \mu^{\prime}\right)}\left(\varepsilon_{x}+\varepsilon_{y}+\varepsilon_{z}\right), \\
\sigma_{z} & =\frac{E^{\prime}}{1-\mu^{\prime}} \varepsilon_{z}+\frac{\mu^{\prime} E^{\prime}}{\left(1-\mu^{\prime}\right)\left(1-2 \mu^{\prime}\right)}\left(\varepsilon_{x}+\varepsilon_{y}+\varepsilon_{z}\right), \\
\tau_{x y} & =G^{\prime} \gamma_{x y}, \\
\tau_{y z} & =G^{\prime} \gamma_{y z}, \\
\tau_{z x} & =G^{\prime} \gamma_{z x} .
\end{aligned}
$$

Equation (11) shows that, when the disc cutter is working, the change in rock strain directly influences the change in cutting resistance whose counterforce is cutting force. Obviously, when the drifting footage per revolution of TBM remains the same, as shown in Eq. (11) the lower the strain, the lower the cutting force of disc cutters. And furthermore, tunnelling energy required by TBM is low, and the wear of rock-breaking cutters is also low, thus reducing TBM project costs. Figures 3, 4, 5, 6, and 7 present the law of the change in rock strain with different penetrations of disc cutter in terms of No.9 involved in a certain project adopting traditional installation and forward-slanting installation.

Assuming $\varepsilon_{x 0}, \varepsilon_{y 0}, \varepsilon_{z 0}, \gamma_{x y 0}, \gamma_{y z 0}$, and $\gamma_{z x 0}$ respectively represent the strain when the disc cutter with traditional installation penetrates the rock to a certain depth, $\sigma_{x 0}, \sigma_{y 0}$, 


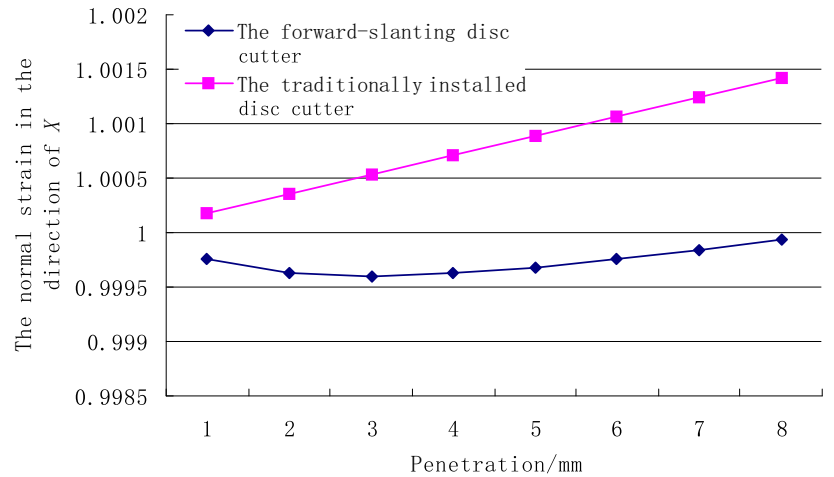

Fig. 3 The normal strain contrast at No.9 between the forward-slanting and traditional installation in the direction of $X$

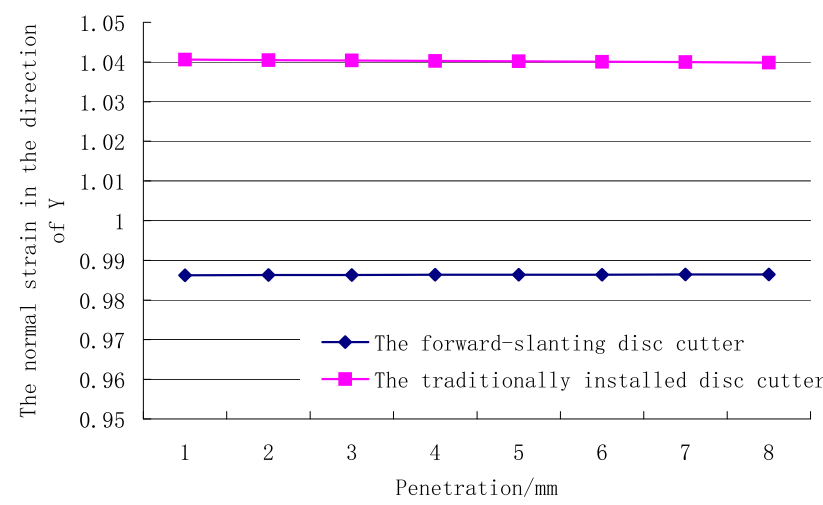

Fig. 4 The normal strain contrast at No.9 between the forward-slanting and traditional installation in the direction of $Y$

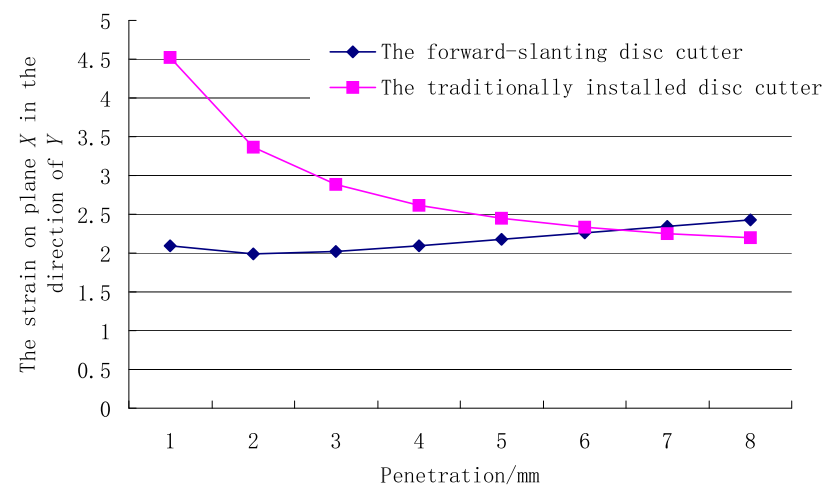

Fig. 5 The shear strain contrast at No.9 between the forward-slanting and traditional installation on plane $X$ in the direction of $Y$

$\sigma_{z 0}, \tau_{x y 0}, \tau_{y z 0}$, and $\tau_{z x 0}$ the corresponding stress. Figures 3 , $4,5,6$, and 7 show $\varepsilon_{x 0} \geqslant \varepsilon_{x}, \varepsilon_{y 0} \geqslant \varepsilon_{y}, \varepsilon_{z 0} \geqslant \varepsilon_{z}, \gamma_{x y 0} \geqslant$ $\gamma_{x y}, \gamma_{y z 0} \geqslant \gamma_{y z}$, and $\gamma_{z x 0} \geqslant \gamma_{z x}$; Equation (11) shows $\sigma_{x 0} \geqslant \sigma_{x}, \sigma_{y 0} \geqslant \sigma_{y}, \sigma_{z 0} \geqslant \sigma_{z}, \tau_{x y 0} \geqslant \tau_{x y}, \tau_{y z 0} \geqslant \tau_{y z}$, and $\tau_{z x 0} \geqslant \tau_{z x}$, and the cutting force of the disc cutter is the integral of the above-mentioned strain at the contact area. According to integral theorem, the cutting force of the disc cutter with forward-slanting installation is small, yet the cutting effect remains the same (penetration being identical).

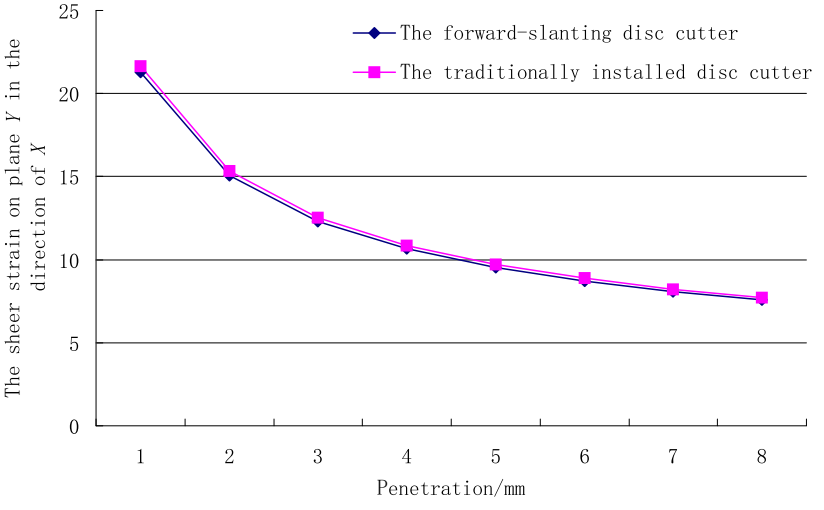

Fig. 6 The shear strain contrast at No.9 between the forward-slanting and traditional installation on plane $Y$ in the direction of $X$

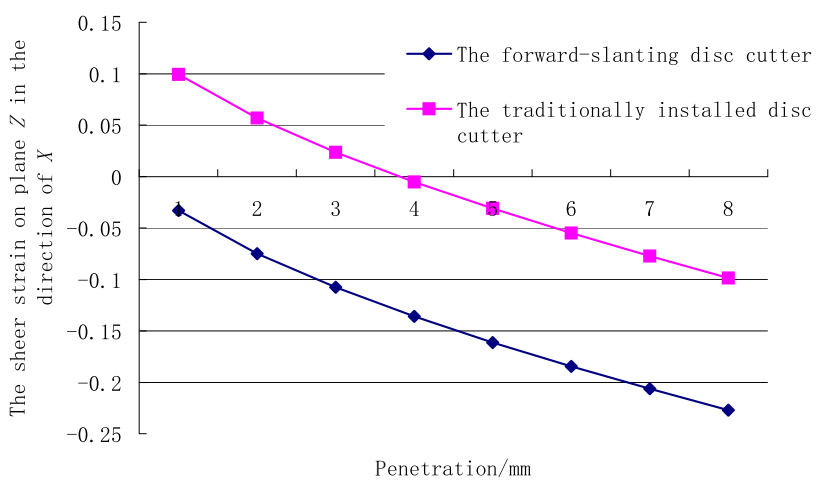

Fig. 7 The shear strain contrast at No.9 between the forward-slanting and traditional installation on plane $Z$ in the direction of $X$

\section{Conclusion}

To solve the practical problems such as high energy consumption, wear of disc cutters during the working process of TBM, a model regarding forward-slanting installation of disc cutters is developed and micro-displacement theory related to the model is also presented. An in-depth contrastive analysis is carried out of the interactive mechanical principles between rocks, the working object, and disc cutters traditionally installed and disc cutters forward-slantingly installed, with the following conclusion arrived at:

(1) Provided that the cutting distance of the cutter head per revolution remains the same, the rock deformation in the case of forward-slantingly installed disc cutters is less than that with the traditionally installed disc cutter. The corresponding interactive strain between disc cutters forward-slantingly installed and rocks is also lower than that of the traditional one. Hence the resulted friction strain between disc cutters and rocks is reduced and wear of disc cutters is decreased, thereby energy consumption of breaking rock per unit drops.

(2) Provided that the rock-breaking energy is the same, the disc cutter with forward-slanting installation has a better 
rock-breaking effect than that with disc cutter installed in a traditional way, that is, the longer the life of disc cutters, the longer the drilling length, which thus not only shortens the working time of TBM, but also reduces its cost.

Acknowledgments This project is supported by National Natural Science Foundation of China (Grant 51475163) and National Hightech R\&D Program of China (863 Program, Grant 2012AA041803).

Open Access This article is distributed under the terms of the Creative Commons Attribution 4.0 International License (http://creativecomm ons.org/licenses/by/4.0/), which permits unrestricted use, distribution, and reproduction in any medium, provided you give appropriate credit to the original author(s) and the source, provide a link to the Creative Commons license, and indicate if changes were made.

\section{References}

1. Jalali, S., Naghadehi, M.Z.: Development of a new laboratory apparatus for the examination of the rotary-percussive penetration in tunnel boring machines. Tunn. Undergr. Space Technol. 33, 88-97 (2013)

2. Teale, R.: The concept of specific energy in rock drilling. Int. J. Rock Mech. Min. Sci. Geomech. Abstr. 2, 57-73 (1965)

3. Pariseau, W.G., Fairhurst, C.: The force-penetration characteristic for wedge penetration into rock. Int. J. Rock Mech. Min. Sci. Geomech. Abstr. 4, 165-180 (1967)

4. Nishimatsu, Y.: The mechanics of rock cutting. J. Int. J. Rock Mech. Min. Sci. Geomech. Abstr. 9, 261-270 (1972)

5. Roxborough, F.F., Phillips, H.R.: The mechanical properties and cutting characteristics of the bunter sandstone. Report, Transport and Road Research Laboratory, Crowthorne, UK (1975)

6. Roxborough, F.F., Phillips, H.R.: Rock excavation by disc cutter. Int. J. Rock Mech. Min. Sci. Geomech. Abstr. 12, 361-366 (1975)

7. Ozdemir, L., Miller, R., Wang, F.D., et al.: Mechanical tunnel boring, predicton, and machine design. National Science Foundation, Washington, DC (1976)

8. Wang, F.D., Ozdemir, L.: Tunnel boring penetration rate and machine design. TRB Research Records No.684, Tunn. Undergr. Struct., ISSN:0361-1981, 21-28 (1978)

9. Lindqvist, P.A.: Rock fragmentation by indentation and disc cutting, [Ph.D. Thesis]. University of Lulea, Lulea, Sweden (1982)
10. Cook, N.G.W., Hood, M., Tsai, F.: Observation of crack growth in hard rock loaded by an indenter. Int. J. Rock Mech. Min. Sci. Geomech. Abstr. 21, 97-104 (1984)

11. Lindqvist, P.A., Suarez del Rio, L.M., Montoto, M., et al.: Rock indentation database, SKB Project, Report, PR-44-94-023 (1994)

12. Kou, S.Q.: Some basic problems in rock breakage by blasting and by indentation, [Ph.D. Thesis]. Lulea University of Technology, Lulea, Sweden (1995)

13. Liu, H.Y.: Numerical modelling of the rock fracture process under mechanical loading, licentiate Thesis, Lulea University of Technology, Lulea, Sweden (2003)

14. Kou, S.Q., Liu, H.Y., Lindqvist, P.A., et al.: Rock fragmentation mechanisms induced by a drill bit. Int. J. Rock Mech. Min. Sci. 41, 527-532 (2004)

15. Innaurato, N., Oggeri, C., Oreste, P.P., et al.: Experimental and numerical studies on rock breaking with TBM tools under high stress confinement. Rock Mech. Rock Eng. 40, 429-451 (2006)

16. Gertsch, R., Gertsch, L., Rostami, J.: Disc cutting tests in Colorado Red Granite: implications for TBM performance prediction. Int. J. Rock Mech. Min. Sci. 44, 238-346 (2007)

17. Liu, S.Y., Du, C.L., Cui, X.X.: Research on the cutting force of a pick. Min. Sci. Technol. 19, 514-517 (2009)

18. Cho, J.W., Jeon, S., Yu, S.H., et al.: Optimum spacing of TBM disc cutters: a numerical simulation using the three-dimensional dynamic fracturing method. Tunn. Undergr. Space Technol. 25, 230-244 (2010)

19. Moon, T., Oh, J.: A study of optimal rock-cutting conditions for hard rock TBM using the discrete element method. Rock Mech. Rock Eng. 45, 837-849 (2012)

20. Liu, Y., Shu, D.W.: Coupled bending-torsion vibration of a homogeneous beam with a single delamination subjected to axial loads and static end moments. Acta Mech. Sin. 30, 607-614 (2014)

21. Zhang, Z.H., Meng, L., Sun, F.: Rock deformation equations and application to the study on slantingly installed disc cutter. Acta Mech. Sin. 30, 540-546 (2014)

22. Zhang, Z.H., Sun, F.: The three-dimension model for the rockbreaking mechanism of disc cutter and analysis of rock-breaking forces. Acta Mech. Sin. 28, 675-682 (2012)

23. Zhang, Z., Meng, L., Sun, F.: Design theory of full face rock tunnel boring machine transition cutter edge angle and its application. Chin. J. Mech. Eng. 26, 541-546 (2013)

24. Zhang, Z.H., Ye, D.H., Yuan, X.: A study of rock mechanical properties under the effect of the wedge-shaped blade head. J. Basic Sci. Eng. 985, 6-978 (2011) 